\title{
Interaction between the P1 protein of Mycoplasma pneumoniae and receptors on HEp-2 cells
}

\author{
Correspondence \\ M. Drasbek \\ drasbek@medmicro.au.dk
}

Received 24 June 2007

Revised 17 July 2007

Accepted 20 July 2007

\author{
M. Drasbek, ${ }^{1}$ G. Christiansen, ${ }^{1}$ K. R. Drasbek, ${ }^{2}$ A. $\mathrm{Holm}^{3}$ and S. Birkelund ${ }^{1,3}$ \\ ${ }^{1}$ Institute of Medical Microbiology and Immunology, Bartholin Building, University of Aarhus, \\ DK-8000 Aarhus C, Denmark \\ ${ }^{2}$ Department of Molecular Biology, Gustav Wieds Vej 10C, University of Aarhus, DK-8000 Aarhus \\ C, Denmark \\ ${ }^{3}$ Loke Diagnostics ApS, Sindalsvej 17, DK-8240 Risskov, Denmark
}

\begin{abstract}
The human pathogen Mycoplasma pneumoniae can cause atypical pneumonia through adherence to epithelial cells in the respiratory tract. The major immunogenic protein, P1, participates in the attachment of the bacteria to the host cells. To investigate the adhesion properties of $\mathrm{P} 1$, a recombinant protein ( $\mathrm{rP} 1-\mathrm{II})$ covering amino acids $1107-1518$ of the $\mathrm{P} 1$ protein was produced. This protein inhibited the adhesion of $M$. pneumoniae to human HEp-2 cells, as visualized in a competitive-binding assay using immunofluorescence microscopy. Previous studies have shown that mAbs that recognize two epitopes in this region of $\mathrm{P} 1$ also reduce M. pneumoniae adhesion. Therefore, peptides covering these epitopes, of 8 and 13 aa, respectively, were synthesized to further investigate the adhesion region. None of these synthetic peptides reduced the binding of $M$. pneumoniae to the receptors on the host cells. Instead, 10 overlapping synthetic peptides covering the whole of $\mathrm{rP} 1$-II were evaluated in the competitivebinding assay using immunofluorescence microscopy. A reduction in the number of $M$. pneumoniae microcolonies was seen, which was confirmed for five peptides using a POLARstar OPTIMA reader to measure fluorescence intensity. The number of $M$. pneumoniae microcolonies adhering to the host cells was significantly reduced by these five peptides. Further investigations showed that inhibiting peptide 7 (amino acids 1347-1396) of the major adhesin protein P1 bound directly to host receptors, suggesting that the observed M. pneumoniae-inhibiting peptides occupied HEp-2 receptors, which are otherwise available for P1-mediated M. pneumoniae adhesion.
\end{abstract}

\section{INTRODUCTION}

Mycoplasma pneumoniae is a human pathogen that colonizes the upper and lower respiratory tract, causing pneumonia. It attaches to ciliated epithelial cells in the respiratory tract, where it induces ciliostasis that protects the mycoplasma from removal by the mucociliary clearance mechanism of the host (Waites \& Talkington, 2004). A key characteristic of $M$. pneumoniae is the lack of a cell wall, which allows exchange of different components between the host membrane and the mycoplasma membrane after adhesion (Razin et al., 1981). Apart from respiratory-tract cells, M. pneumoniae adheres to many different types of eukaryotic cells in vitro, e.g. HEp-2, HeLa, macrophages and erythrocytes (Razin et al., 1981).

Abbreviations: DAPI, 6-diamino-2-phenylindole; IMF, indirect immunofluorescence microscopy; TBTU, o-benzotriazol-1-yl- $N, N, N^{\prime}, N^{\prime}$-tetramethyluronium tetrafluoroborate.
M. pneumoniae is elongated and consists of a longer taillike rear end, a thicker body part and a frontal attachment organelle. This organelle is composed of a network of proteins, of which the adherence accessory proteins are thought to confer the tip structure, and to underlie mycoplasma mobility as well as the clustering of a network of adhesins at the tip (Bredt, 1979; Waites \& Talkington, 2004). The $P 1$ protein, which is mainly concentrated at the tip, is one of the major adhesins in M. pneumoniae, and the loss of P1 through mutation results in reduced adherence to host cells (Krause, 1996). Furthermore, a fragment of the C-terminal part of the $\mathrm{P} 1$ protein has been shown previously to be immunogenic, as sera from M. pneumoniae patients show a reaction with this fragment (Drasbek et al., 2004). Recently, it has been seen that anti-P1 antibodies reduce the gliding speed of $M$. pneumoniae, thus hampering the mobility of the bacterium and possibly its ability to find suitable host adhesion receptors (Seto et al., 2005). 
Attachment of bacteria to host cells is one of the key steps of infection and often relies on an interaction between bacterial adhesins and oligosaccharides on the host cells. These interactions are usually mediated by binding of lectins present on the bacterial surface to oligosaccharide chains bound to glycoproteins and glycolipids on eukaryotic cells (Thomas \& Brooks, 2004). This is probably also the case for $M$. pneumoniae attachment, since reduced adhesion of M. pneumoniae has been demonstrated when human alveolar epithelial cells (A549) are pre-treated with tunicamycin, which degrades oligosaccharides (Thomas \& Brooks, 2004). In addition, other studies have shown that the adhesion of $M$. pneumoniae to tracheal epithelial cells decreases by $50-65 \%$ when they are treated with neuraminidase, which cleaves terminal acylneuraminic residues from oligosaccharides, glycoproteins and glycolipids. Likewise, heat, methiolate, glutaraldehyde and formalin also inhibit the adhesion of $M$. pneumoniae to eukaryotic cells (Gabridge \& Taylor-Robinson, 1979; Razin et al., 1981).

Adhering mycoplasmas contain several adhesins, and $M$. pneumoniae expresses at least three different adhesins, termed P1, P30 and P116, suggesting that there are multiple receptors for M. pneumoniae on the host cells (Razin \& Jacobs, 1992; Svenstrup et al., 2002). Monospecific antibodies raised against P116 block the adhesion of $M$. pneumoniae to HEp-2 cells, as do antibodies against the P30 protein (Baseman et al., 1987). It is, however, unclear whether this inhibition is direct or results from steric hindrance of neighbouring structures. Recently, elongation factor $\mathrm{Tu}$ and the pyruvate dehydrogenase $\mathrm{E} 1 \beta$ subunit have been shown to bind fibronectin, which is usually found in the extracellular matrix of eukaryotic cells (Dallo et al., 2002). In addition, the surface protein P65 contains an Arg-Gly-Asp (RGD) domain, raising the possibility that $M$. pneumoniae attaches to binding sites for fibronectin on the host cell (Krause, 1996).
Recently, it has been shown that antibodies against the C-terminal part of the M. pneumoniae P1 protein and the homologous Mycoplasma genitalium MgPa protein inhibit host-cell adhesion of M. pneumoniae and M. genitalium, respectively (Svenstrup et al., 2002). mAbs that recognize epitopes in this region (Dallo et al., 1988; Jacobs et al., 1990) also inhibit the binding of M. pneumoniae to host cells. However, no inhibition is observed using antibodies that target the $\mathrm{N}$-terminal parts of the proteins. In mycoplasma-free extracts, P1 binds to host cells, suggesting a direct role for P1 in host receptor binding (Krause, 1998; Razin \& Jacobs, 1992). Thus, the anti-P1 antibody inhibition of adhesion could originate from blocking of the adhesion region of P1. However, simple steric hindrance by the antibodies could also explain the observed inhibition. Therefore, in the present study, we applied a competitivebinding assay to determine the attachment-mediating region of the C-terminal part of $\mathrm{P} 1$. A recombinant protein covering this part of $\mathrm{P} 1$ (rP1-II; Fig. 1), as well as several synthetic overlapping peptides covering the same region, was utilized, and both rP1-II and some of the peptides inhibited M. pneumoniae adherence to receptors on HEp-2 cells. Direct binding of one peptide to the host cells was detected using biotinylated peptides, suggesting a direct interaction between the P1 protein and a host cell receptor. Furthermore, this receptor was shared between the peptide and rP1-II, as the binding of the biotinylated peptide was inhibited in a concentration-dependent manner by unmarked peptides and the rP1-II protein.

\section{METHODS}

Preparation of HEp-2 cells for infection with M. pneumoniae. The human epithelial cell line HEp-2 (ATCC) was cultured in TPP tissue-culture flasks containing growth medium [RPMI 1640 medium (Gibco-BRL) with $25 \mathrm{mM}$ HEPES-buffer (0.01 M HEPES, $0.15 \mathrm{M}$ $\mathrm{NaCl}, \mathrm{pH} 7.2$ ) and $10 \%$ sterile filtered fetal calf serum (FCS)], with $10 \mu \mathrm{g}$ gentamicin $\mathrm{ml}^{-1}$. One day prior to M. pneumoniae infection,

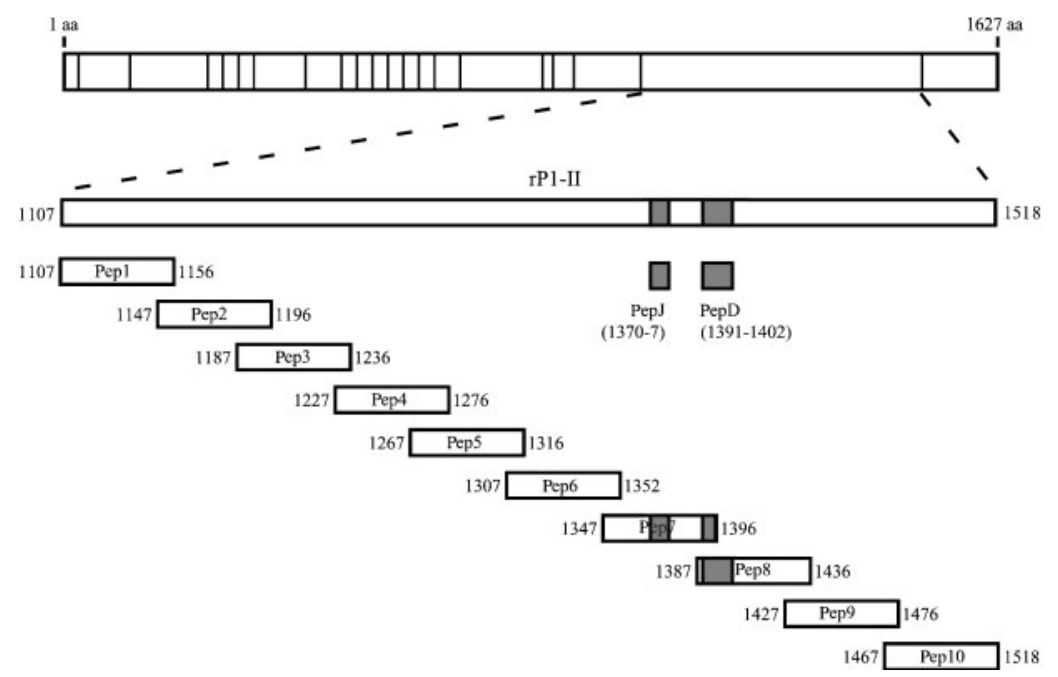

Fig. 1. Schematic illustration of the $P 1$ amino acid sequence. The positions of the UGA codons (tryptophan) are indicated by black lines. The recombinant $\mathrm{rP} 1-\|$ protein covers part of the $\mathrm{C}$-terminal region of the protein (amino acids 1107-1518), while the 12 synthetic peptides cover the same region. The grey boxes denote the two inhibiting antibody-binding regions, pepJ and pepD (Dallo et al., 1988; Jacobs et al., 1990). 
HEp-2 cells were trypsinated $(0.25 \%$ trypsin in PBS with $0.02 \%$ EDTA) and plated in growth medium with $0.05 \%$ penicillin $\left(100 \mathrm{U} \mathrm{ml}^{-1}\right)$. Each well of either a 16-well Lab-Tek chamber slide (Nunc) or a black 96-well Nunclon cell-culture plate (both with optical bottoms) contained 3750 cells per well, while 18750 cells per well were plated in a 24 -well plate containing glass coverslips. The cells were incubated overnight in $5 \% \mathrm{CO}_{2}$ at $37{ }^{\circ} \mathrm{C}$ before $M$. pneumoniae infection.

\section{Preparation of $\boldsymbol{M}$. pneumoniae and $\boldsymbol{M}$. genitalium for infection} of HEp-2 cells. M. pneumoniae strain FH and M. genitalium G37 (ATCC) were cultured in $10 \mathrm{ml} \mathrm{SP} 4$ medium (Tully et al., 1979) in TPP tissue-culture flasks and incubated at $37^{\circ} \mathrm{C}$. After growth for $48 \mathrm{~h}$, the medium changed colour from red to orange, indicating the exponential growth phase (Clausen et al., 2001). The mycoplasmas were scraped into $10 \mathrm{ml}$ growth medium containing penicillin $\left(100 \mathrm{U} \mathrm{ml}^{-1}\right)$. To reduce the number of self-aggregating features of M. pneumoniae, the suspension was sheared through a 27 gauge needle five times and adjusted to a concentration of approximately $9 \times 10^{7}$ colour changing units $\mathrm{ml}^{-1}$ before infection of the HEp-2 cells.

Generation of the recombinant protein rP1-II. The recombinant protein $M$. pneumoniae $\mathrm{rP1}$-II aa 1107-1518 and the recombinant $M$. genitalium protein $\mathrm{rMgPa}$ aa $628-1350$ were produced as described previously (Svenstrup et al., 2002). To reduce the concentration of urea in the purification buffer, the proteins were first diluted to $0.2 \mathrm{mg} \mathrm{ml}^{-1}$ in growth medium and then dialysed against the same medium with $10 \mu \mathrm{g}$ gentamicin $\mathrm{ml}^{-1}$ for $2 \mathrm{~h}$ at $4{ }^{\circ} \mathrm{C}$.

Synthesis of peptides. Two epitopes, pepJ (Jacobs et al., 1990) and pepD (Dallo et al., 1988), of 8 and 13 aa, respectively, were synthesized (Fig. 1). Additional peptides of $44-52$ aa covering rP1-II were designed with an overlap of 6-10 aa (Fig. 1), together with a random peptide with the sequence RIYKGVIQAIQKSDEGHPFRAYLESEVAISEELVQKYSNSALGHVNCTIKELRRLFLVDDLVDSLK. Peptides were synthesized stepwise on a fully automated peptide synthesizer ABI 433 (Applied Biosystems) using the Fmoc strategy. Peptides were synthesized on a TentaGel S RAM resin [Fluka; s (substitution) $0.2 \mathrm{mM} \mathrm{g}^{-1}$ ] to generate peptide amides. Fmocprotected amino acids in suitable side-chain-protected forms as well as the coupling reagent $o$-benzotriazol-1-yl- $N, N, N^{\prime}, N^{\prime}$-tetramethyluronium tetrafluoroborate (TBTU) were obtained from Fluka. After completion of assembly, peptides were cleaved from the resin, with simultaneous side-chain deprotection, using trifluoroacetic acid and triisopropylsilane/water as scavenger. Filtrates were concentrated in vacuo and peptides precipitated with ether. Precipitates were lyophilized from acetic acid/water. Molecular mass verification was made by MS using MALDI-TOF for all peptides except peptide 1, the size of which was instead verified by SDS-PAGE, since it fragmented during MS.

Biotinylation of peptides. Biotinylation was carried out after completion of peptide assembly while the peptide, with protected side groups, was still attached to the resin, using biotin (Sigma-Aldrich) and TBTU as coupling reagents. The biotinylated peptide was cleaved from the resin and treated as described above.

Competitive-binding assay with rP1-II. The dialysed rP1-II recombinant protein $(10,20,40$ or $80 \mu \mathrm{l})$ was incubated with HEp2 cells grown in chamber slides for $30 \mathrm{~min}$ at $37{ }^{\circ} \mathrm{C}$. The M. pneumoniae RPMI suspension $(50 \mu \mathrm{l}$ per well $)$ was added and incubated overnight at $37^{\circ} \mathrm{C}$. The HEp-2 cells were washed twice in PBS and fixed in $100 \%$ methanol at $4{ }^{\circ} \mathrm{C}$ for $1 \mathrm{~min}$. To detect the adhering mycoplasmas, the infected HEp-2 cells were incubated with primary antibodies (PabFH or PabG37) diluted 1:500 for $30 \mathrm{~min}$ at $37{ }^{\circ} \mathrm{C}$ (Svenstrup et al., 2002), washed with PBS and incubated with $100 \mu \mathrm{l}$ per well of secondary FITC-conjugated 'Affinipure' goat anti-rabbit ( $\mathrm{GaR}) \operatorname{IgG}(\mathrm{H}+\mathrm{L})$ (Jackson Immuno Research Laboratories) diluted $1: 100$ in PBS with $0.002 \%$ Evans blue, for $30 \mathrm{~min}$ at $37^{\circ} \mathrm{C}$. The wells were washed twice with PBS before attached $M$. pneumoniae were visualized using a fluorescence microscope.

Competitive-binding assay with synthetic peptides. The $M$. pneumoniae suspension was incubated with each of the synthetic peptides $\left(20 \mu \mathrm{g} \mathrm{ml}^{-1}\right.$; $\sim 10^{15}$ molecules) for $30 \mathrm{~min}$ at $37^{\circ} \mathrm{C}$. HEp-2 cells were incubated with the mycoplasma peptide suspension $(50 \mu \mathrm{l}$ per well) overnight. The samples were prepared for indirect immunofluorescence microscopy (IMF) as described in the competitivebinding assay with rP1-II.

IMF. The samples prepared for the adhesion detection and the competitive-binding assays were investigated by IMF. A drop of antifade solution $\left[p\right.$-phenyldiamine dihydrochloride $\left(1 \mu \mathrm{g} \mathrm{ml}^{-1}\right)$ in $10 \%$ PBS and $90 \%, \mathrm{v} / \mathrm{v}$, glycerol, $\mathrm{pH} 9.0$ ] was placed between the slide and the coverslip. Fluorescence microscopy was performed with a Leitz DMR fluorescence microscope (Leica).

Indirect immunofluorescence for fluorometric measurement by POLARstar. The M. pneumoniae suspension was mixed with each of the synthetic peptides $\left(20 \mu \mathrm{g} \mathrm{ml}^{-1}\right)$ or a dilution series was made with $M$. pneumoniae to obtain a standard curve. HEp-2 cells were plated in black 96-well Nunclon cell-culture plates with optical bottoms, as described above, and incubated either with the mycoplasma peptide suspension or with diluted mycoplasmas $(50 \mu \mathrm{l}$ per well) overnight. The samples were prepared as described above for the rP1-II competitive-binding assay for IMF, with the exception that PBS with 6-diamino-2-phenylindole (DAPI; 1/1000) was added instead of antifade to each well before the fluorescence measurement was carried out using a POLARstar OPTIMA reader (BMC Labtech). Emission and excitation filters were 488 and $520 \mathrm{~nm}$ for FITC and 526 and $532 \mathrm{~nm}$ for DAPI, respectively.

Immunofluorescence with fluorescent beads. HEp-2 cells were prepared as described above and incubated with biotinylated peptide 1 or peptide $7\left(80 \mu \mathrm{g} \mathrm{ml}^{-1}\right)$ for $30 \mathrm{~min}$ at $37^{\circ} \mathrm{C}$. In the peptide competition experiment, HEp-2 cells were preincubated with unmarked peptides or proteins for $30 \mathrm{~min}$ before the $30 \mathrm{~min}$ incubation with biotinylated peptides. The cells were fixed as described for the competition assay with rP1-II. To detect receptorbound peptides, the cells were incubated with $10 \mu \mathrm{l}$ NeutrAvidincoated yellow/green fluospheres (Invitrogen), diluted 1:10 in PBS for $10 \mathrm{~min}$ at $4{ }^{\circ} \mathrm{C}$, washed and investigated using IMF.

Statistical analysis. In each experimental round, all samples were tested in duplicate or triplicate, as well as being repeated on different experimental days. Results are expressed as mean values with SDs. $P$ values were calculated using Student's $t$ test for normally distributed data (fluorescent intensity measurements), while the non-parametric Mann-Whitney test was used for the remaining data (microcolony counting) with a significance level of $P<0.05$ (two-tailed).

\section{RESULTS}

\section{Competitive-binding assay with rP1-II}

The immunogenic $\mathrm{P} 1$ protein is clustered at the tip organelle and participates in pathogen-host interactions (Baseman et al., 1982). The recombinant $\mathrm{rP} 1-\mathrm{II}$ protein contained a $6 \times$ His tag, which was used for nickel-affinity purification under denaturing conditions in a urea-containing buffer 
(Svenstrup et al., 2002). However, urea is toxic to HEp-2 cells, so rP1-II was diluted to $0.2 \mathrm{mg} \mathrm{ml}^{-1}$ and subjected to dialysis against growth medium for $2 \mathrm{~h}$ prior to use. Four different concentrations of rP1-II were incubated with HEp2 cells for $30 \mathrm{~min}$ at $37^{\circ} \mathrm{C}$ before live M. pneumoniae were added. The infected cells were incubated overnight at $37^{\circ} \mathrm{C}$, washed in PBS and fixed with methanol. Adherent $M$. pneumoniae were detected with pabFH, a polyclonal antibody raised against M. pneumoniae whole-cell proteins, and visualized using FITC-conjugated IgG antibody. To fluorescently visualize HEp-2 cells, the fixed cells were counterstained with Evans blue (red fluorescence, Fig. 2a) prior to immunofluorescent detection of attached $M$. pneumoniae. To estimate the inhibition of adhesion, the bound M. pneumoniae microcolonies were counted on individual HEp-2 cells that were not in contact with other cells. Each microcolony was counted as one, regardless of the individual size of the microcolonies. In the positive control without recombinant proteins, an average of 25 microcolonies per HEp-2 cell (range 16-33 microcolonies per HEp-2 cell) was counted (Fig. 2b). Preincubation with rP1II prior to addition of M. pneumoniae to the HEp-2 cells clearly reduced the number of $M$. pneumoniae microcolonies associated with the HEp-2 cells (Fig. 2c) in a dose-dependent manner, as 10, 20, 40 and $80 \mu \mathrm{lP} 1-\mathrm{II}\left(2 \mu \mathrm{g} \mathrm{ml}{ }^{-1}\right)$ resulted in 17.3, 16, 8.5 and $6 \mathrm{M}$. pneumoniae microcolonies per HEp-2 cell, respectively. Furthermore, shortening the $M$. pneumoniae incubation time to $1 \mathrm{~h}$ showed a similar reduction in the number of microcolonies, suggesting that host cell receptors are persistently occupied by the recombinant proteins (data not shown). In contrast, no inhibition of $M$. pneumoniae adhesion was observed using a recombinant protein $(\mathrm{rMgPa})$ from the closely related $M$. genitalium (data not shown). Thus, rP1-II seems to compete with M. pneumoniae for binding to receptors on HEp-2 cells.

\section{Competitive-binding assay with two synthetic peptides covering the two known epitopes}

To further analyse the region of attachment, two synthetic peptides (pepJ and pepD; grey boxes in Fig. 1) which were recognized by inhibiting antibodies were tested in the competitive-binding assay. The number of microcolonies was counted and compared to the positive control without peptides. Both peptides showed a slight reduction in the number of M. pneumoniae microcolonies, $21.8 \%$ for pepJ and $16.9 \%$ for pepD, compared to the positive control without peptides. However, neither peptide reduced the binding of $M$. pneumoniae to HEp-2 cells significantly ( $P=0.27$ and 0.41 , respectively), as was also the case for a synthetic peptide spanning a region from pepJ to pepD (data not shown). To ascertain that the counting of microcolonies on the individual cells was not biased by the researcher, the fluorescence intensity of bound $M$. pneumoniae was measured using the POLARstar OPTIMA in black 96-well plates. The nuclear fluorescent stain DAPI was included as a measure of the number of host cells. The fluorescence measurements were fairly stable between wells and plates, showing a uniform distribution of HEp-2 cells in the plates. The amount of bound mycoplasma was calculated using a standard curve made from a dilution series of $M$. pneumoniae. Only slight variations in calculated M. pneumoniae concentration were seen when pepJ and pepD were tested for inhibition, confirming the manually counted results (data not shown).

\section{Competitive-binding assay with 10 synthetic peptides}

Because no significant competition was seen between $M$. pneumoniae and the two short peptides (pepJ and pepD), another approach to narrow down the adhesion region was utilized. Ten peptides (44-52 aa) covering the same region of $\mathrm{P} 1$ as $\mathrm{rP} 1-\mathrm{II}$ were designed with $6-10$ aa overlaps (Fig. 1). These peptides were then tested in the competitivebinding assay to estimate the inhibitory effect of each peptide on M. pneumoniae adherence. As a negative control, the closely related $M$. genitalium was included. After incubation with the peptides, adherent $M$. pneumoniae on HEp-2 cells were detected as described for rP1-II, while $M$. genitalium were detected using an antibody raised against M. genitalium whole-cell proteins.

The attachment of mycoplasmas to host cells was estimated by counting microcolonies on solitary HEp- 2 cells and by measuring fluorescence intensity using the POLARstar as before. Between 49 and 94 HEp-2 cells were selected for each peptide in order to estimate the number of $M$. pneumoniae microcolonies per HEp-2 cell (Fig. 3). Likewise,
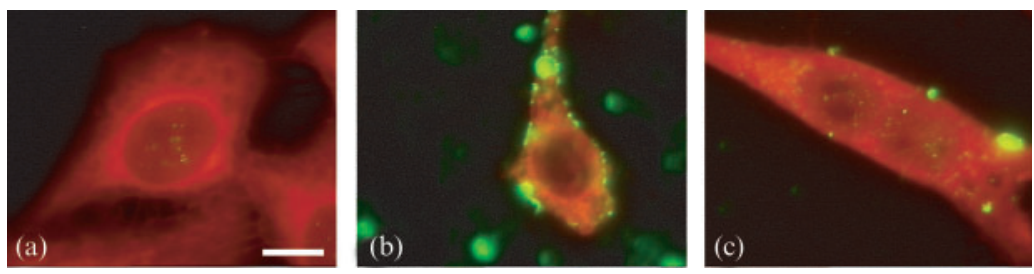

Fig. 2. Competitive-binding assay, with the recombinant $\mathrm{rP1}$-II protein visualized using immunofluorescence microscopy. Evans blue stains the entire HEp-2 cell red. The $M$. pneumoniae microcolonies are visualized with the primary antibody $\mathrm{pab}(\mathrm{FH})$ and a FITCconjugated (green fluorescent) secondary antirabbit IgG antibody. (a) Uninfected HEp-2 cells; (b) HEp-2 cells incubated with $M$. pneumoniae; (c) HEp-2 cells incubated with $80 \mu \mathrm{rP1}$-II before infection with $M$. pneumoniae. Bar, $10 \mu \mathrm{m}$. 

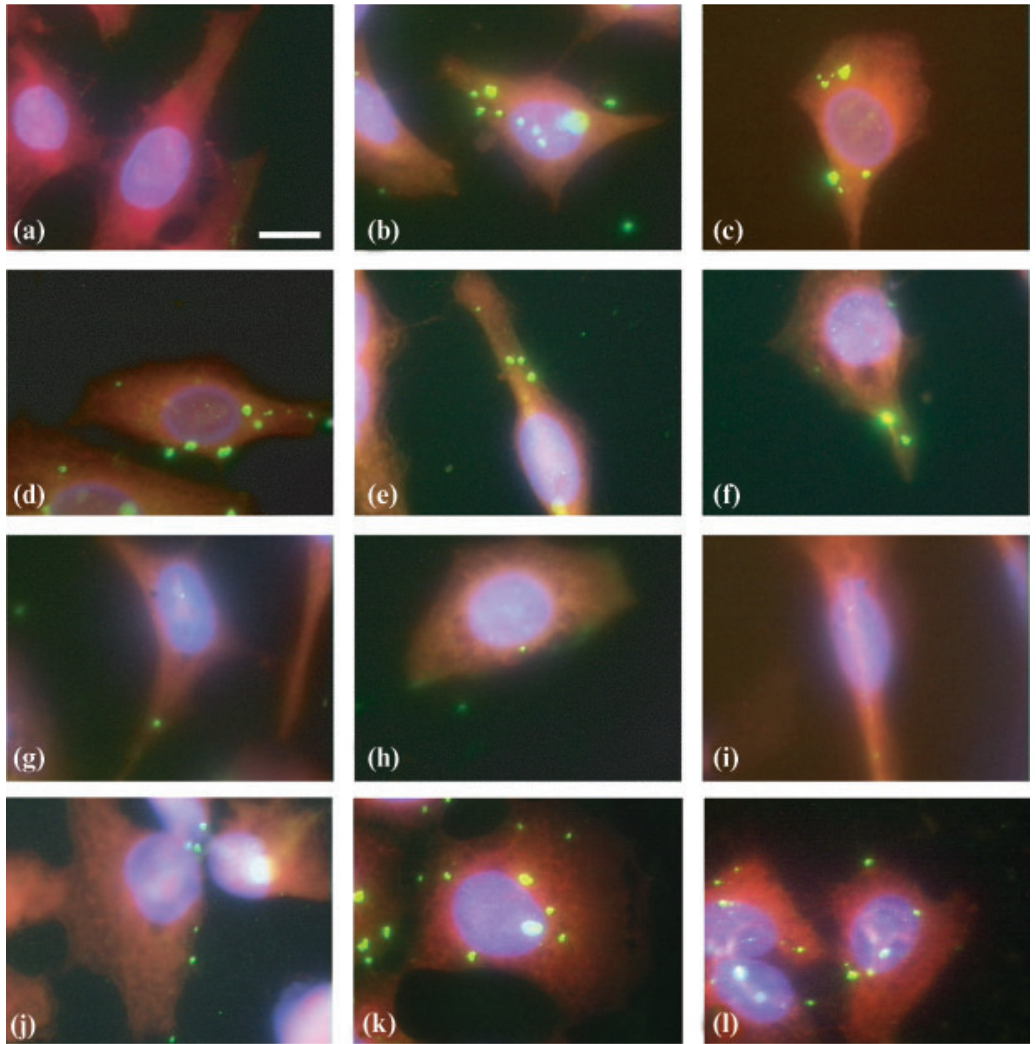

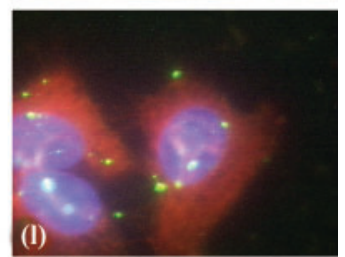

Fig. 3. Competitive-binding assay with 10 synthetic overlapping peptides using immunofluorescence microscopy. The HEp-2 cells are stained with Evans blue (red) and DAPI (blue). The M. pneumoniae microcolonies attached to the HEp-2 cells are detected by the polyclonal antibody pab(FH) and FITC-conjugated secondary antibody (green dots). (a) Negative control showing uninfected HEp-2 cells with no binding of pab(FH); (b) positive control without peptides showing $M$. pneumoniae microcolonies; (c-l) preincubation with peptides $1-10$, respectively. Bar, $10 \mu \mathrm{m}$.
M. genitalium microcolonies on 17-26 HEp-2 cells were counted for each peptide. In the negative control (Fig. 3a), no $M$. pneumoniae microcolonies were detected, while a few mycoplasma microcolonies were detected with peptides 3-8 (Fig. 3e-j) compared to the positive control (Fig. 3b). In contrast, the numbers of microcolonies after competition with peptides $1-2$ and 9-10 (Fig. 3c-d and $\mathrm{k}-\mathrm{l}$ ) were closer to the number in the positive control. These results were obtained after preincubating the peptides with $M$. pneumoniae before HEp-2 cell infection. However, preincubating the peptides with HEp-2 cells and/ or reducing the $M$. pneumoniae incubation time to $1 \mathrm{~h}$ did not alter the results noticeably.

All peptides significantly reduced the adhesion of $M$. pneumoniae, but to varying degrees. A histogram of the mean number of microcolonies showed a bell-shaped curve (Fig. 4, Table 1) with peptides 1-3 and 9-10 exhibiting the smallest reduction in adherence compared to peptides 4-8, with peptide 7 (amino acids 1347-1396) showing the greatest inhibition, $78.9 \%(P<0.0001)$. The adherence of M. genitalium to HEp-2 cells was not inhibited by any of the 10 peptides (data not shown). A slightly higher number of M. genitalium microcolonies was detected when the peptides were added.

The fluorescence intensity of bound $M$. pneumoniae in competition with the 10 synthetic peptides was also measured using the POLARstar OPTIMA to obtain an objective measure of bound M. pneumoniae. The amount of bound mycoplasma was calculated using a standard curve, as described above. Eight peptides (peptides 2-9) could compete with $M$. pneumoniae in binding to the HEp-2 cells with a reduction of 2-16.6\% (Table 2). Five of

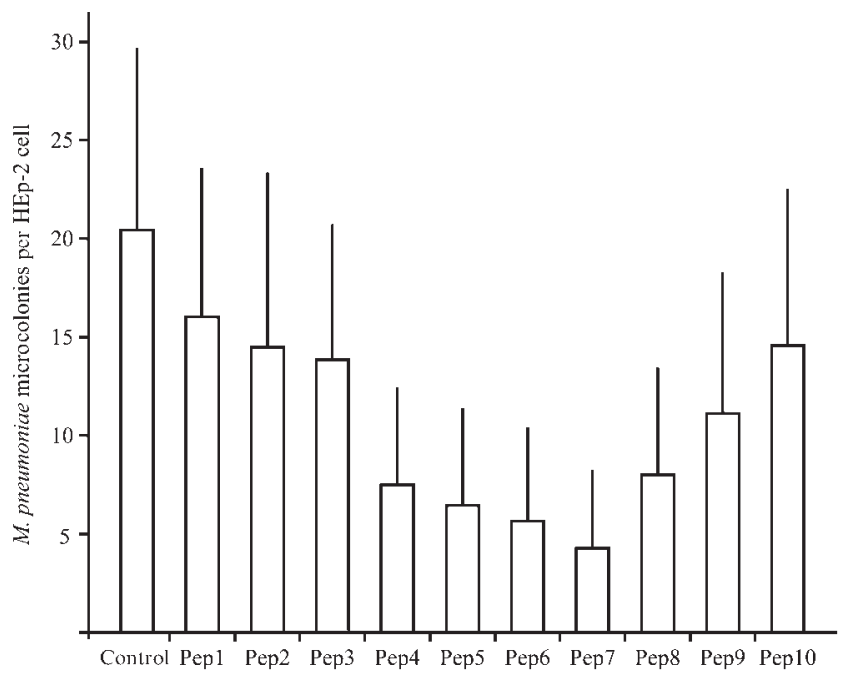

Fig. 4. Summary of the competitive-binding assay with $M$. pneumoniae and the 10 synthetic peptides. The histogram shows the mean $\pm S D$ (bars) of the number of microcolonies after incubation with the peptides. 
Table 1. Inhibition of $M$. pneumoniae adhesion by the synthetic P1-derived peptides

The mean number of $M$. pneumoniae microcolonies per HEp-2 cell was counted after IMF. $n$, Number of individual HEp- 2 cells counted.

\begin{tabular}{|lcccc|}
\hline Peptide & $\begin{array}{c}\text { Mean count of } \\
\text { M. pneumoniae } \\
\text { microcolonies }\end{array}$ & $\begin{array}{c}\text { Relative } \\
\text { inhibition } \\
(\%)\end{array}$ & $\boldsymbol{n}$ & $\begin{array}{c}\text { P value } \\
\text { (two-tailed) }\end{array}$ \\
\hline Control & $20.4 \pm 9.2$ & & 71 & \\
Peptide 1 & $16.0 \pm 7.5$ & 21.6 & 81 & 0.001 \\
Peptide 2 & $14.5+8.8$ & 28.9 & 69 & 0.0001 \\
Peptide 3 & $13.9 \pm 6.8$ & 31.9 & 68 & 0.0001 \\
Peptide 4 & $7.5 \pm 4.9$ & 63.0 & 74 & 0.0001 \\
Peptide 5 & $6.4 \pm 4.9$ & 68.6 & 94 & 0.0001 \\
Peptide 6 & $5.7 \pm 4.7$ & 72.0 & 91 & 0.0001 \\
Peptide 7 & $4.3 \pm 3.9$ & 78.9 & 56 & 0.0001 \\
Peptide 8 & $8.0 \pm 5.4$ & 60.8 & 48 & 0.0001 \\
Peptide 9 & $11.1 \pm 7.1$ & 45.6 & 67 & 0.0001 \\
Peptide 10 & $14.5 \pm 7.9$ & 28.9 & 56 & 0.0001 \\
& & & & \\
\hline
\end{tabular}

these (peptides 4-7 and peptide 9) reduced binding significantly $(P<0.05$, Student's $t$ test $)$, and this corresponded to the results of microcolony counting. No inhibition of M. genitalium was observed (data not shown).

\section{Binding of peptides to HEp-2 cells}

As the peptides clearly reduced the attachment of $M$. pneumoniae to host cells, it was interesting to see whether the peptides associated directly with host cells, thereby causing a reduction in $M$. pneumoniae adherence. To investigate the binding of the peptides to HEp-2 cells, two

Table 2. FITC fluorescence intensity of $M$. pneumoniae on host cells

The fluorescence intensity of FITC-marked M. pneumoniae microcolonies was normalized to the positive control. $n$, Number of wells scanned.

\begin{tabular}{|lccc|}
\hline Peptide & $\begin{array}{c}\text { Normalized } \\
\text { fluorescence }\end{array}$ & $\boldsymbol{n}$ & $\begin{array}{c}\boldsymbol{P} \text { value } \\
\text { (two-tailed) }\end{array}$ \\
\hline Control & $1.00 \pm 0.13$ & 18 & \\
Peptide 1 & $1.07 \pm 0.24$ & 15 & 0.357 \\
Peptide 2 & $0.98 \pm 0.13$ & 15 & 0.666 \\
Peptide 3 & $0.97 \pm 0.21$ & 15 & 0.823 \\
Peptide 4 & $0.83 \pm 0.14$ & 19 & $0.001^{\star}$ \\
Peptide 5 & $0.85 \pm 0.16$ & 16 & $0.005^{\star}$ \\
Peptide 6 & $0.85 \pm 0.15$ & 18 & $0.004^{\star}$ \\
Peptide 7 & $0.88 \pm 0.08$ & 18 & $0.002^{\star}$ \\
Peptide 8 & $0.98 \pm 0.15$ & 18 & 0.595 \\
Peptide 9 & $0.90 \pm 0.14$ & 16 & $0.046 \dagger$ \\
Peptide 10 & $1.01 \pm 0.12$ & 15 & 0.750 \\
\hline
\end{tabular}

${ }^{\star} P<0.01$.

$\dagger P<0.05$. peptides were selected, peptide 1 , which caused the smallest inhibition, and peptide 7 , which caused significant $M$. pneumoniae inhibition. These peptides were biotinylated at the N-terminal end and incubated with HEp-2 cells for $30 \mathrm{~min}$ at $37^{\circ} \mathrm{C}$. The cultures were washed and methanol-fixed, and bound peptides were visualized using NeutrAvidin-coated yellow/green fluospheres (beads) (Fig. 5). No fluorescence was seen from the biotinylated peptides without beads (Fig. 5a), while the beads showed a sporadic binding pattern without biotinylated peptide (Fig. 5b). The clustering of the beads on the HEp-2 cells after preincubation with peptide 1 suggested an interaction between the peptide and the HEp-2 cells (Fig. 5c). A more striking interaction was observed with peptide 7 (Fig. 5d), which correlates with the ability of the peptide to inhibit M. pneumoniae adhesion.

The number of beads per HEp- 2 cell was counted on 18-31 HEp- 2 cells for peptides 1 and 7 and the control. For the control, $4.6 \pm 4.1$ beads per HEp-2 cell without biotinylated peptide were found. In comparison, the mean numbers of beads bound with peptide 1 and peptide 7 were $15.8 \pm 8.4$ and $59.3 \pm 21.2$ beads per HEp-2 cell, respectively. This suggests that peptide 7 interacts with HEp-2 cells through a specific receptor. To investigate whether the binding of peptide 7 was genuine and shared the same host receptor as P1 and thereby also M. pneumoniae, a peptide-competition
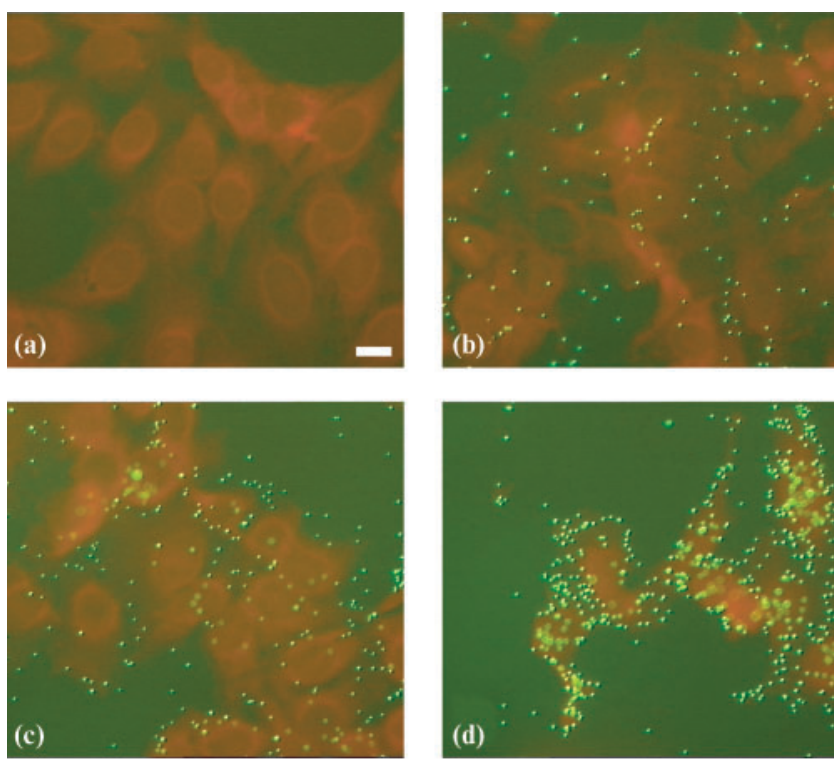

Fig. 5. Binding of peptides to HEp-2 cells. The biotinylated peptides attached to the HEp-2 cells were detected with NeutrAvidin-coated yellow/green fluospheres. (a) Negative control with peptide 7 and without yellow/green fluospheres shows no fluorescence; (b) HEp-2 cells without peptides show a diffuse distribution of the yellow/green fluospheres; (c) peptide 1 associates with the HEp-2 cells as seen by the binding of the beads; (d) peptide 7 strongly clusters the beads on the HEp-2 cells. Bar, $10 \mu \mathrm{m}$. 
assay was performed. Close-to-confluent HEp-2 cells were pre-incubated with varying concentrations of unmarked peptide 7 for $30 \mathrm{~min}$, and then challenged with biotinylated peptide 7 for $30 \mathrm{~min}$. As almost no solitary HEp-2 cells were present in these preparations, the total number of bound beads was counted in consecutive pictures covering the entire well in a vertical line, thus generating higher numbers than reported for the initial experiment. The average number of beads per microscope frame decreased as the concentration of unmarked peptide 7 was increased (Table 3). Likewise, increasing amounts of rP1-II decreased the number of biotinylated peptide 7 on the host cells. Neither a non-specific control peptide nor $\mathrm{rMgPa}$ from $M$. genitalium inhibited the binding of biotinylated peptide 7 (data not shown). These results show a pronounced direct interaction between the synthetic peptide 7 and the HEp-2 cells, an interaction that could be blocked by rP1-II, suggesting that the peptide inhibits M. pneumoniae adhesion by occupying receptors otherwise recognized by the $\mathrm{P} 1$ protein.

\section{DISCUSSION}

The $\mathrm{P} 1$ protein is one of the major $M$. pneumoniae adhesins, expressed all over the surface of the pathogen but clustered at the tip structure. This clustering is thought to play an important role in cytadherence of $M$. pneumoniae to host cells, since $M$. pneumoniae lacking the $\mathrm{P} 1$ protein on the membrane fail to adhere to the host cells (LayhSchmitt \& Harkenthal, 1999). In addition, P1 is the most immunogenic $M$. pneumoniae protein, and antibodies recognizing this protein are always found in human serum samples from M. pneumoniae-infected patients ( $\mathrm{Hu}$ et al.,

Table 3. Competitive binding of synthetic peptides and recombinant proteins

The mean number of beads associated with a confluent layer of host cells per microscopic frame is given. The total number of bound beads was counted in consecutive pictures covering the entire well in a vertical line to ensure randomness. The control was counted after incubation with $80 \mu \mathrm{g} \mathrm{ml}^{-1}$ biotinylated peptide 7. Unmarked rP1-II and peptide 7 inhibited biotinylated peptide 7 attachment. $n$, Number of frames counted.

\begin{tabular}{|lccr|}
\hline Peptide & $\begin{array}{c}\text { Concentration } \\
\left(\boldsymbol{\mu} \mathbf{g ~ m}^{-\mathbf{1}}\right)\end{array}$ & $\begin{array}{c}\text { Mean number of } \\
\text { beads per frame }\end{array}$ & $\boldsymbol{n}$ \\
\hline Control & & $205.2 \pm 89.9$ & 22 \\
rP1-II & 100 & $95.6 \pm 37.4$ & 11 \\
& 50 & $114.7 \pm 42.2$ & 8 \\
& 25 & $131.0 \pm 51.6$ & 8 \\
Peptide 7 & 10 & $136.5 \pm 32.5$ & 8 \\
& 100 & $134.3 \pm 83.0$ & 10 \\
& 50 & $158.3 \pm 51.5$ & 8 \\
& 25 & $172.0 \pm 49.2$ & 5 \\
& 10 & $191.3 \pm 72.7$ & 14 \\
\hline
\end{tabular}

1983; Jacobs et al., 1985, 1989). The C-terminal part of the protein has been found to be the immunogenic region, as determined using human sera, and monospecific and monoclonal antibodies (Chaudhry et al., 2005; Drasbek et al., 2004). Recently, using monospecific antibodies, it has been found that the C-terminal part of P1 is surfaceexposed (Svenstrup et al., 2002). Furthermore, in the present study, a direct interaction between the P1 protein and host cell receptors was found, since the recombinant protein $\mathrm{rP} 1-\mathrm{II}$ clearly reduced adhesion of $M$. pneumoniae.

The model of P1 contains several surface-exposed loops, which have been suggested to form three domains, thereby building a tertiary adherence complex (Jacobs et al., 1989, 1990, 1995). Epitope mapping of the P1 protein has led to the suggestion that the N-terminal region and two additional domains, D1 and D2, are extracellular and arranged in close proximity (Fig. 6). This would enable the three different loops to form a triangular structure, which might exhibit a stronger adherence capacity due to cooperative binding to the receptor molecule (Gerstenecker \& Jacobs, 1990; Razin \& Jacobs, 1992). However, the adhesion-mediating protein sequences might not be identical to the sequences described as immunogenic epitopes. Indeed, adhesion-inhibiting mAbs targeting sequences not recognized by human serum samples have been described (Jacobs et al., 1990). In the present study, the region of the P1 protein which mediates adhesion to the host cells was mapped to the D2 domain. Sequences in this region (Fig. 6) have previously been linked to cytadherence, since mAbs targeting these sequences reduce M. pneumoniae adhesion to the host cells (Dallo et al., 1988; Jacobs et al., 1990). This inhibition is probably caused by steric hindrance of the large antibodies, because no significant reduction in the adhesion of $M$. pneumoniae to the HEp-2 cells was seen with pepJ and pepD, which cover these epitopes. In addition, peptide 7, which showed the greatest inhibitory effect, included pepJ and part of pepD, suggesting that the host receptor binding sequence of the P1 protein is to be found in the C-terminal half of rP1-II.

The adhesion region of $M$. pneumoniae was narrowed using 44-50 aa synthetic peptides (Fig. 6). Five peptides inhibited the adhesion of M. pneumoniae to HEp-2 cells significantly, as measured by both manual counting and automatic measurements. However, the amount of reduction determined by the two methods differed. Manual counting of M. pneumoniae only included microcolonies associated with solitary host cells, giving a precise measure of attached M. pneumoniae microcolonies. However, these counts could be biased by the researcher, and therefore the unbiased fluorometric POLARstar measurements of the entire well of a black 96-well plate were included. Some basal background fluorescence was anticipated as $M$. pneumoniae attaches directly to plastic. These microcolonies would be unaffected by the host-receptor-blocking peptides, leading to lower relative reductions in $M$. pneumoniae-generated fluorescence. The synthetic peptides 


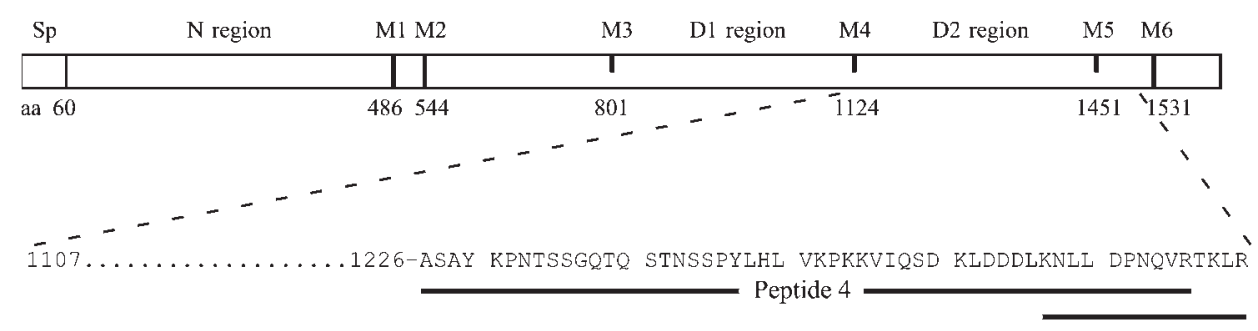

QSEGTDHSTQ PQFQSLKTIT PVEGTSSGNL SSVLSGGGAG GGSSGSGQSG VDLSPVEKVS GWLVGQLPST SDGNTSSTNN - Peptide $5 \longrightarrow$ Peptide $6 \longrightarrow$ LAPNTNTGND VVGVGRLSES NAAKMNDDVD GIVRTPLAEL LDGEGQTADT GPQSVKEKSF DQIDFNRLFT HPVTDLFDFV - Peptide $7 \longrightarrow$ Peptide $8 \longrightarrow$ TMLVYDQYIP LFIDIPASVN PKMVRIKVLS FDTNEQ $1476 \ldots \ldots \ldots \ldots \ldots 1518$

Peptide $9 \longrightarrow$

Fig. 6. Membrane-associated domains and the rP1-ll region. Adapted from Jacobs et al. (1990) and Eisenberg et al. (1984). The membrane-associated domains were identified using the program http://www.expasy.org/tools/pscale/ Hphob.Eisenberg.html using the following parameters: window size, 9; relative weight for window edges, $100 \%$. The black lines M1-M6 indicate the membrane-associated domains, and the aa number marks the first amino acid in the transmembraneassociated domain. The $\mathrm{rP1}-\mathrm{Il}$ region (amino acids 1107-1518) is shown, and the sequences of peptides 4-9 are included. The sequences of pepJ (Jacobs et al., 1990) and pepD (Dallo et al., 1988) are in bold type. Sp, signal peptide.

inhibited the adhesion of M. pneumoniae to host cells to varying degrees. A similar graduation of adhesion inhibition has been observed elsewhere in the investigation of the outer-membrane protein P5-homologous fimbrin adhesin protein from Haemophilus influenzae, in which both short and long peptides covering the protein show differing degrees of inhibition of bacterial adhesion (Novotny et al., 2000). The inhibition region, peptides $4-9$, is flanked by the two membrane-associated regions, M4 and M5, in the extracellular D2 region (Fig. 6), suggesting that the D2 region binds directly to the host cell. Indeed, peptide 7 of P1 was found to bind a specific host receptor that was shared with the P1 protein, suggesting that the inhibiting peptides function through the blockage of specific host cell receptors. Similarly, a fragment of the P29 adhesin from Mycoplasma fermentans inhibits the adhesion of the bacteria to HeLa cells through the blockage of host cell receptors (Leigh \& Wise, 2002).

In the present study, only a partial inhibition was seen, although an excess of peptides was added. This might be due to the difference in size and mobility of M. pneumoniae, which is larger and more mobile than the small and immobile peptides. Additionally, the observed partial inhibition could reflect the interaction of other $M$. pneumoniae proteins with receptors on the host cell, as a stronger inhibition of adhesion was seen previously when antibodies raised against P116 and the C-terminal part of P1 were combined (Svenstrup et al., 2002). This P116 protein has been identified elsewhere as a host-receptorbinding protein under the name of $\mathrm{P} 2$ together with the P1 protein and HMW3 (Krause et al., 1982), and it has been reported that the extracellular protein fibronectin is bound by elongation factor $\mathrm{Tu}$ and the pyruvate dehydrogenase E1 $\beta$ subunit from M. pneumoniae (Dallo et al., 2002). It is therefore likely that adhesion of $M$. pneumoniae to host cells is a more complex process than the receptormediated binding of peptide 7 of P1 to host cells, as described in the present study. To obtain a more complete understanding of the host $-M$. pneumoniae interaction, a model system of human ciliated respiratory cells should be used.

Such an understanding could be used to block host cell receptors to which pathogenic microorganisms adhere. This may be considered as an alternative strategy to prevent colonization by the pathogen. Indeed, a synthetic peptide mimicking an adhesion epitope of the oral bacterium Streptococcus mutans inhibits the colonization of tooth surfaces by this micro-organism (Younson \& Kelly, 2004). Thus, the introduction of $M$. pneumoniae-derived peptides that block human adhesion receptors might in the future reduce or even prevent $M$. pneumoniae infections.

\section{ACKNOWLEDGEMENTS}

We are grateful to Karin S. Sørensen for skilled laboratory assistance and to Lisbet W. Pedersen for linguistic revision of this paper. This work was financially supported by the Faculty of Health Sciences PhD program, University of Aarhus, EU FP6: NoE EPG LSHB-CT2005 512061, and Fonden til Lægevidenskabens Fremme. M.D. initiated the study, designed and performed the assays and wrote the first draft of the manuscript; K.R.D. performed the POLARstar measurements and their analysis, and commented on the manuscript; A.H. made the synthetic peptides; S. B. and G.C. supervised the study, provided the research facilities and commented on the manuscript. 


\section{REFERENCES}

Baseman, J. B., Cole, R. M., Krause, D. C. \& Leith, D. K. (1982). Molecular basis for cytadsorption of Mycoplasma pneumoniae. J Bacteriol 151, 1514-1522.

Baseman, J. B., Morrison-Plummer, J., Drouillard, D., PuleoScheppke, B., Tryon, V. V. \& Holt, S. C. (1987). Identification of a 32-kilodalton protein of Mycoplasma pneumoniae associated with hemadsorption. Isr J Med Sci 23, 474-479.

Bredt, W. (1979). Motility. In The Mycoplasmas, pp. 141-155. Edited by M. F. Barile \& S. Razin. New York: Academic Press.

Chaudhry, R., Nisar, N., Hora, B., Chirasani, S. R. \& Malhotra, P. (2005). Expression and immunological characterization of the carboxy-terminal region of the P1 adhesin protein of Mycoplasma pneumoniae. J Clin Microbiol 43, 321-325.

Clausen, H. F., Fedder, J., Drasbek, M., Nielsen, P. K., Toft, B., Ingerslev, H. J., Birkelund, S. \& Christiansen, G. (2001). Serological investigation of Mycoplasma genitalium in infertile women. Hum Reprod 16, 1866-1874.

Dallo, S. F., Su, C. J., Horton, J. R. \& Baseman, J. B. (1988). Identification of P1 gene domain containing epitope(s) mediating Mycoplasma pneumoniae cytoadherence. J Exp Med 167, 718-723.

Dallo, S. F., Kannan, T. R., Blaylock, M. W. \& Baseman, J. B. (2002). Elongation factor $\mathrm{Tu}$ and $\mathrm{E} 1 \beta$ subunit of pyruvate dehydrogenase complex act as fibronectin binding proteins in Mycoplasma pneumoniae. Mol Microbiol 46, 1041-1051.

Drasbek, M., Nielsen, P. K., Persson, K., Birkelund, S. \& Christiansen, G. (2004). Immune response to Mycoplasma pneumoniae $\mathrm{P} 1$ and $\mathrm{P} 116$ in patients with atypical pneumonia analyzed by ELISA. BMC Microbiol 4, 7.

Eisenberg, D., Schwarz, E., Komaromy, M. \& Wall, R. (1984). Analysis of membrane and surface protein sequences with the hydrophobic moment plot. J Mol Biol 179, 125-142.

Gabridge, M. G. \& Taylor-Robinson, D. (1979). Interaction of Mycoplasma pneumoniae with human lung fibroblasts: role of receptor sites. Infect Immun 25, 455-459.

Gerstenecker, B. \& Jacobs, E. (1990). Topological mapping of the P1-adhesin of Mycoplasma pneumoniae with adherence-inhibiting monoclonal antibodies. J Gen Microbiol 136, 471-476.

Hu, P. C., Huang, C. H., Collier, A. M. \& Clyde, W. A., Jr (1983). Demonstration of antibodies to Mycoplasma pneumoniae attachment protein in human sera and respiratory secretions. Infect Immun 41, 437-439.

Jacobs, E., Schopperle, K. \& Bredt, W. (1985). Adherence inhibition assay: a specific serological test for detection of antibodies to Mycoplasma pneumoniae. Eur J Clin Microbiol 4, 113-118.

Jacobs, E., Gerstenecker, B., Mader, B., Huang, C. H., Hu, P. C., Halter, R. \& Bredt, W. (1989). Binding sites of attachment-inhibiting monoclonal antibodies and antibodies from patients on peptide fragments of the Mycoplasma pneumoniae adhesin. Infect Immun 57, 685-688.
Jacobs, E., Pilatschek, A., Gerstenecker, B., Oberle, K. \& Bredt, W. (1990). Immunodominant epitopes of the adhesin of Mycoplasma pneumoniae. J Clin Microbiol 28, 1194-1197.

Jacobs, E., Bartl, A., Oberle, K. \& Schiltz, E. (1995). Molecular mimicry by Mycoplasma pneumoniae to evade the induction of adherence inhibiting antibodies. J Med Microbiol 43, 422-429.

Krause, D. C. (1996). Mycoplasma pneumoniae cytadherence: unravelling the tie that binds. Mol Microbiol 20, 247-253.

Krause, D. C. (1998). Mycoplasma pneumoniae cytadherence: organization and assembly of the attachment organelle. Trends Microbiol 6, $15-18$.

Krause, D. C., Leith, D. K., Wilson, R. M. \& Baseman, J. B. (1982). Identification of Mycoplasma pneumoniae proteins associated with hemadsorption and virulence. Infect Immun 35, 809-817.

Layh-Schmitt, G. \& Harkenthal, M. (1999). The 40- and $90-\mathrm{kDa}$ membrane proteins (ORF6 gene product) of Mycoplasma pneumoniae are responsible for the tip structure formation and P1 (adhesin) association with the Triton shell. FEMS Microbiol Lett 174, 143-149.

Leigh, S. A. \& Wise, K. S. (2002). Identification and functional mapping of the Mycoplasma fermentans P29 adhesin. Infect Immun 70, 4925-4935.

Novotny, L. A., Jurcisek, J. A., Pichichero, M. E. \& Bakaletz, L. O. (2000). Epitope mapping of the outer membrane protein P5homologous fimbrin adhesin of nontypeable Haemophilus influenzae. Infect Immun 68, 2119-2128.

Razin, S. \& Jacobs, E. (1992). Mycoplasma adhesion. J Gen Microbiol 138, 407-422.

Razin, S., Kahane, I., Banai, M. \& Bredt, W. (1981). Adhesion of mycoplasmas to eukaryotic cells. Ciba Found Symp 80, 98-118.

Seto, S., Kenri, T., Tomiyama, T. \& Miyata, M. (2005). Involvement of P1 adhesin in gliding motility of Mycoplasma pneumoniae as revealed by the inhibitory effects of antibody under optimized gliding conditions. J Bacteriol 187, 1875-1877.

Svenstrup, H. F., Nielsen, P. K., Drasbek, M., Birkelund, S. \& Christiansen, G. (2002). Adhesion and inhibition assay of Mycoplasma genitalium and M. pneumoniae by immunofluorescence microscopy. J Med Microbiol 51, 361-373.

Thomas, R. \& Brooks, T. (2004). Common oligosaccharide moieties inhibit the adherence of typical and atypical respiratory pathogens. $J$ Med Microbiol 53, 833-840.

Tully, J. G., Rose, L. D., Whitcomb, R. F. \& Wenzel, R. P. (1979). Enhanced isolation of Mycoplasma pneumoniae from throat washings with a newly modified culture medium. J Infect Dis 139, 478-482.

Waites, K. B. \& Talkington, D. F. (2004). Mycoplasma pneumoniae and its role as a human pathogen. Clin Microbiol Rev 17, 697-728.

Younson, J. \& Kelly, C. (2004). The rational design of an anti-caries peptide against Streptococcus mutans. Mol Divers 8, 121-126.

Edited by: C. Citti 